\title{
EL OBJETO INTERNALIZADO DE WINNICOTT EN MI PRÁCTICA CLÍNICA ${ }^{1}$
}

\author{
Carmen Domingo Peña ${ }^{2}$ \\ La Rioja, España
}

\begin{abstract}
El presente trabajo tiene como objetivo hacer un recorrido por algunos de los planteamientos más importantes de Winnicott y cómo mi comprensión de ellos se ve aplicada en mi quehacer analítico con niños y adolescentes. A lo largo de este texto recojo mis propias reflexiones sobre cómo mientras trabajo con mis pacientes ayudo a que juntos co-construyamos una tercera zona o zona intermedia que se encuentre a caballo entre lo interno y lo externo y cómo eso afecta después a favorecer el desarrollo madurativo que había quedado estancado. Winnicott se ha convertido en un objeto de referencia al que acudo en los momentos donde siento que me tambaleo en mi práctica clínica y se ha transformado en una especie de objeto transicional que me permite atravesar las zonas de incertidumbre e inseguridades típicas del inicio del trabajo como psicoterapeuta.
\end{abstract}

Palabras clave: Infancia, Adolescencia, Zona Intermedia, Objeto internalizado, Winnicott.

Through this paper I would like to address some of the main contributions of Winnicott theoretical framework and how my comprehension of them has have an impact on my clinical practice with children and adolescents. Along this work I collect some of my thoughts of how I help my patients to co-create a third area or an intermediate area between the patient's inner and outer world and how this has an impact to reshape their developmental blueprint. Winnicott has become an internalized object that helps me coping with moments of insecurity during my clinical practice. In conclusion, he has become my personal transitional object that allows me to deal with the uncertainty and insecurity that involve the first steps of analytic practice.

Key Words: Infancy, Adolescence, Intermediate area, Internalized object, Winnicott.

English Title: The internalized object of Winnicott in my clinical practice.

\section{Cita bibliográfica / Reference citation:}

Domingo Peña, C. (2019). El objeto internalizado de Winnicott en mi práctica clínica. Clínica e Investigación Relacional, 13 (2): 441-454. [ISSN 1988-2939] [Recuperado de www.ceir.info ] DOI: 10.21110/19882939.2019.130208

\footnotetext{
${ }^{1}$ Trabajo original ganador de la VIII Edición del Certamen "El Devenir del Terapeuta" (2018) convocado por el Instituto de Psicoterapia Relacional (Madrid).

${ }^{2}$ Psicóloga y psicoterapeuta relacional infanto-juvenil. E-mail: carmendomingog1@gmail.com
} 


\section{Introducción}

Cuando uno comienza su andadura en la práctica de la psicoterapia busca en los textos de autores clásicos, y no tan clásicos, un refugio cuando siente la incertidumbre o la inseguridad de los comienzos. Inevitablemente encontramos autores que nos transmiten familiaridad y comodidad entre sus propuestas y que por alguna razón nos hacen sentir identificados. De alguna manera yo siempre he encontrado en las propuestas de Winnicott y en su quehacer analítico una especie de sintonía con mi propia personalidad y forma de entender la psicoterapia. Quizás es por la calidez con la que trata a sus pacientes, también por el interés y el trabajo que ha realizado con niños y adolescentes. De todas formas no es mi intención resolver mi propia paradoja, yo (bebé en el mundo del trabajo como psicoanalista) he creado el objeto de Winnicott, pero éste ya estaba ahí, esperando que se le crease y se lo denominara objeto cargado (Winnicott, 1953 y 1971).

El objeto internalizado de Winnicott se ha convertido en mi particular fenómeno transicional al que acudo en momentos de desesperación, incertidumbre e inseguridad al enfrentarme al trabajo con niños y adolescentes. Winnicott afirmaba que en el proceso hacia la maduración y el desarrollo emocional del infante "al principio el niño únicamente está solo en presencia de alguien" (1958), y así es como muchas veces me pienso yo en el trabajo con mis pacientes. En definitiva, delante del paciente o de la familia sólo me hallo yo; sin embargo, me acompañan en mi cabeza los múltiples objetos internos como mis autores de referencia, mis supervisoras pasadas y presentes, mi terapeuta y las lecturas y participaciones en seminarios y experiencias vicarias en las supervisiones grupales con mis compañeros que me permiten experimentar que no me encuentro sola en el trabajo con los pacientes, especialmente en los momentos difíciles y de mayor angustia.

Durante este trabajo voy a exponer a través de pequeñas viñetas clínicas cómo la obra de Winnicott ha ido guiando mi trabajo a través del juego. Por eso, voy a centrarme muy especialmente en su obra Realidad y Juego (Winnicott, 1971) eligiendo fragmentos y reflexiones que realiza a lo largo de esta obra plasmadas en mis intervenciones y sesiones con los jóvenes que presentaré. Es probable que aparezcan menciones a otros autores que también están representados en mi mente como referentes como puede ser Mitchell, aunque Winnicott será sin duda el protagonista indiscutible.

\section{Qué hay de Winnicott en mí}

La forma de hacer y de estar con los pacientes de Winnicott es algo que cuando escucho seminarios sobre él, leo sus obras o pienso en su forma de trabajar me conecta con un 
sentimiento de familiaridad, una especie de conexión mente con mente. Esto me ha llevado a reflexionar qué hay de Winnicott en mí. Por qué cuando escucho su forma de trabajar tengo esa sensación de sencillez- sin ser sencillas de llevar a cabo sus propuestasy de gran familiaridad con mi forma de hacer. Siento que en mi manera de trabajar con mis pacientes tengo la capacidad de conectar con ellos de formas muy especiales, especialmente con casos graves. Tengo la capacidad de ser una terapeuta suficientemente buena llevando a cabo funciones de sostén. Una cierta facilidad para ver a través de su sufrimiento, salir a su encuentro y conectar con la parte de su self más verdadero y espontáneo.

Entonces, qué hay de mi propia historia que me permite hacer esto. Reflexionando tanto sola como en mi propio proceso personal pude pensar en mi propia historia de vínculos, en que en mi entorno cada vez que yo salía al encuentro de alguien, de afecto, de algún gesto, de sostén he encontrado a personas que me recibían y respondían ante mi necesidad lo suficientemente bien. Personas que a lo largo de mi desarrollo me han sostenido y han encontrado el delicado equilibrio entre el afecto y la frustración, entre la permisividad y la autonomía y los límites necesarios, convirtiéndose así en figuras suficientemente buenas. También pienso en el valor de la mirada que he recibido de los otros hacia mí, una mirada cálida, afectuosa y bondadosa que es la misma que muchas veces me encuentro yo misma devolviendo a mis pacientes.

Quizás, todas estas experiencias de aprendizaje con mis otros significativos han permitido que en mi propia práctica clínica pueda ofrecer a mis pacientes lo mismo que conmigo han hecho, un espacio de seguridad y de sostén y la posibilidad de habitar y utilizar una parte de mí para sentir, jugar, bromear y transitar por los aspectos dolorosos de su self y poder juntos co-construir una forma más integrada y espontánea de vivir.

\section{Una segunda oportunidad para la integración}

Al igual que el desarrollo del bebé, quiero comenzar con una viñeta clínica de un caso donde se tuvo que trabajar en la construcción del objeto. Un caso donde la permanencia del objeto aún era inexistente y tuve que poner en marcha todos los mecanismos de holding, handling y presentación del objeto que plantea Winnicott en sus obras para permitir la integración el primero de los tres logros fundamentales en el desarrollo madurativo y emocional de un bebé. 


\section{Caso A}

A es una niña de 6 años. En la exploración inicial se muestra suspicaz, con dificultades para el mantenimiento de la atención en la relación dual. Un discurso desorganizado, no lineal y con un lenguaje pobre que apenas puedo entender porque el desarrollo del habla ha sido históricamente costoso. Se muestra hiperexcitada, con una euforia de naturaleza hipomaníaca. De acuerdo con el diagnóstico estructural del niño (Palacio, F. y Dufour, R., 2003) podríamos enmarcar a $A$ en los problemas graves de personalidad de tipo prepsicótica.

Los comienzos con ella fueron muy complejos. Las sesiones eran un caos. El primer foco de nuestro trabajo fue ayudar a $\mathrm{A}$ a orientarse en el espacio y en el tiempo. Todas las sesiones comenzaban- y a día de hoy aún comienzan- mirando juntas el calendario, viendo qué día y hora es y qué actividad hace después. El objetivo era comenzar a integrar la dimensión temporal como la parte más básica de la integración primaria (Abello, A. y Liberman, A., 2011.)

El siguiente paso fue el final de las sesiones. Cada vez que llegaba el momento de finalizar una sesión A entraba en un momento de caos y desintegración. Comenzaba a insultarme, corría por la habitación tirando todos los papeles y juegos de las estanterías, me lanzaba los juguetes, los rompía y se escapaba de la sala. Pude entonces pensar que A no era capaz de terminar el juego porque cada vez que nos despedíamos dejaba de estar presente para ella. Desaparecía. No existía continuidad del objeto y la conectaba con angustias persecutorias y de desintegración a pesar de que en todo momento yo me despedía con la frase "nos vemos la semana que viene el mismo día y a la misma hora. Te estaré esperando con ganas de jugar juntas de nuevo" independientemente de cómo hubiera sido el final de la sesión. Necesitaba destruirme, pero siempre a la semana siguiente seguía ahí. Sobrevivía. Además, tras varias sesiones yo le ofrecía que antes de irnos, debido a que el final era complejo para ella, podríamos despedirnos con un abrazo y un beso (que después de haberme dañado ella me había demandado en alguna ocasión.) Este elemento formaba parte de otro punto clave en la integración primaria, la dimensión psique-soma. Teniendo esto en mente, mi trabajo con ella es quizás más sensorial que con ningún paciente, porque mientras jugamos le cojo la mano mientras le hablo, le acaricio la mano o cuando estamos jugando tranquilas mientras le señalo lo bien que las dos nos sentimos jugando de esta manera paso mi mano por su espalda para acariciarle, en un gesto casi similar a cuando se acuna o se calma a un bebé.

Debo mencionar que para mí fueron difíciles estos comienzos porque resultaban angustiosos y temía el momento de finalizar las sesiones por la dificultad para contenerla. 
En ocasiones tuve que verme redirigiéndole y buscando el contacto físico con ella, sujetándole con calidez y a la vez expresando con palabras que no dejaría que siguiera rompiendo cosas o lanzándome objetos porque los dos nos sentíamos tristes, dolidas y quizás luego ella incluso culposa por haber dañado nuestra relación y que de esta manera le cuidaba y le impedía hacerse daño a sí misma, a mí o al entorno. Ella misma en varios momentos de nuestras sesiones me preguntaba si yo le quería. En definitiva, ella -que tantos problemas tiene en las relaciones sociales y tan rechazada se siente por sus faltas de control físico y verbal- quería saber si yo a pesar de sus deseos de destruirme y de odiarme tan fuertes seguía queriéndole y seguía sobreviviendo. No sólo eso, sino que en mi cabeza yo la pensaba y existía de forma integrada; algo que se le devolvía en el trabajo juntas. Yo era la misma a la que quería y la cual a veces odiaba y deseaba destruir, y yo pese a todo seguía queriéndole y seguía ofreciéndole un beso y un abrazo cada vez que nos despedíamos.

Al cabo de unos meses algo comenzó a cambiar. Los finales de sesión eran cada vez más manejables. Los desbordamientos eran menores y apareció un nuevo elemento de juego en sesión. El juego del escondite. Durante varios meses nos dedicamos a jugar al escondite. Ella se escondía en un lugar que no tenía mucho recoveco para no ser vista y yo juagaba a que no le encontraba. Mientras le buscaba ponía palabras a mis ganas de encontrarle, a mi preocupación por no verle y cuando le encontraba le repetía " $i A n d a$, estás ahí! ¡Qué alegría! ¡Con las ganas que tenía de volver a verte!" Cada vez que se iba yo retomaba mis conversaciones imaginarias con el objeto internalizado de Winnicott y pensaba que ahora ya comenzaba a haber permanencia de objeto. Podíamos despedirnos y ya no desaparecía por completo, sino que podía ser capaz de mantener mi imagen en su cabeza entre sesión y sesión.

Un nuevo paso en el trabajo hacia la integración ha sido recientemente, cuando me enteré que había estado llevándose pequeños juguetes a escondidas. Comenzó entonces a pedir que se quería llevar los dibujos que hacía conmigo. Estaba construyendo su propio objeto transicional entre sesiones. Algo similar al juego del Fort $D a$ al que hace referencia Freud en su libro Más allá del principio de placer (1920.) En esta nueva etapa en la que nos encontramos actualmente ella desea realizar dibujos en sesión y llevárselos. Yo le ofrezco que lo puede volver a traer cuando quiera. Comenzó a querer que juntas dibujáramos algo. Una de esas veces hicimos dos dibujos y uno quiso llevárselo ella y otro me lo dejó a mí para que me acordara de ella, me dijo. Mientras dibujamos yo canto, canto una canción infantil. Pide que la siga cantando y mientras ella dibuja todos los animales que aparecen en dicha canción. Le animo entonces a que al igual que el dibujo, también puede llevarse esta 
canción que cantamos juntas en sesión como otro elemento al que puede recurrir para acordarse de nuestra relación.

Seguimos avanzando y ahora parece que se está conformando ya la primera paradoja que permite la creación de un objeto transicional y que esperemos permitirá la continuidad de su proceso madurativo.

\section{La transicionalidad y la importancia de una mirada distinta}

Qué sucede cuando hay una madre que no responde a las necesidades del infante, una madre que no ve a su hijo como una persona total sino como alguien parcial y que además no es capaz de individualizarse de éste y por tanto impide un adecuado proceso de individuación.

Aquí quiero mostrar un caso que genera una gran preocupación en mí por la gravedad de la patología familiar, y por cómo esto está afectando al desarrollo emocional y a la extremadamente frágil construcción del Yo de este adolescente. Este es un ejemplo de cómo la existencia de una figura sana que devuelva una mirada distinta puede ayudar a taponar el desarrollo de una patología grave.

\section{Caso Y}

Y es un adolescente. Acude a consulta por su comportamiento infantil. Su desarrollo ha sido tórpido y con una gran fragilidad física que ha llevado arrastrando desde el nacimiento y que ha requerido los cuidados de su madre. Existe una relación simbiótica madre e hijo con una grave patología límite da la madre que impide la mentalización de éste y la capacidad de tolerar la diferencia en el proceso de individuación. El estado de ánimo de $Y$ es bajo y su autoconcepto muy pobre. Todo esto genera en el menor una angustia terrible ante la posibilidad de enfrentarse a lo escolar de forma independiente. Además, existe un funcionamiento en proceso primario que conlleva serios problemas para la represión de pensamientos que genera grandes problemas en sus relaciones sociales y en especial con el sexo femenino.

Durante gran parte del trabajo $Y$ ha fantaseado con la idea de que yo pudiera olvidarme de él. Alguna vez incluso solía decirme que no se acordaba de mi nombre. Necesitaba devaluar un vínculo que en su matriz relacional era totalmente nuevo. Era un chico que sólo se le aceptaba si se sometía al dictamen de las demandas maternas. Tal como dice Mitchell en su obra de 1993, "todos los niños se deforman (o más bien adquieren forma gracias a sus 
primeras relaciones significativas [...] el niño, que busca objetos, encuentra a otras personas, se apega a ellas y se conforma de acuerdo a ellas para obtener su reconocimiento." (p.314.) Así, siguiendo con las ideas de Mitchell su matriz relacional estaba configurada por vínculos ambivalentes, donde sólo se le aceptaba si seguía las expectativas de su madre de obtener un hijo académicamente sobresaliente y perfecto y donde su verdadero self jamás había sido mirado.

Mi trabajo comenzó dando cabida a su creatividad y sus habilidades artísticas que permitían validar algo donde se sentía bueno. De alguna manera, parecía sentir que si se vinculaba conmigo traicionaba a su madre, pero yo siempre me mostré disponible y aceptaba sin enfado que se olvidara de mí sabiendo que yo de él nunca me olvidaba y que para mí era alguien especial. En muchos momentos me ha llegado a decir que yo soy una buena persona y que le miro diferente. Que la relación conmigo no vale o no es real porque yo le trato de una forma buena y que no cree que lo merezca porque no es digno de ser mirado así. También he validado y tolerado su odio. Le he ayudado a ponerle palabras para que pueda experimentar que la persona que le quiere también puede ser odiada y aun así sobrevive. He validado que se enfadara conmigo cuando él sentía que no le ayudaba cuando lo necesitaba, es decir, en clase -en el momento donde surgía el conflicto-, yo no estaba presente; o cuando le gustaría que le cuidara y que estuviera con él más veces a la semana y sólo estaba una.

Preocupada por su estado de tristeza y desesperanza decidí regalarle una libreta donde le escribí unas líneas que dejaban claro que había gente para la cual era importante. Incluso donde reflejaba que sus padres aún con sus dificultades también le querían. Ese iba a ser desde ese momento un espacio transicional para la represión. En esa libreta le animaba a que pudiera escribir todo aquello que se le venía a la cabeza y no podía callar. De alguna manera sería una forma de expresar sus pensamientos, ponerlos en algo intermedio entre la vida exterior y la realidad interior, lo que Winnicott llama la zona intermedia o la tercera zona (1971, p.29.) Así, descarga ahí la pulsión primera de llevarlo al acto y en nuestra cita semanal podemos abordar todo aquello que ha sido capaz de reprimir.

En nuestra relación siempre hemos abordado que él para mí es una persona especial, que es importante. A veces me pregunta por el resto de pacientes. También por mis relaciones personales. Pudimos entonces volver a poner en palabras juntos que evidentemente tengo más chicos y tengo personas fuera de mi trabajo que también son importantes para mí pero que puedo ser capaz de albergar en mi mente y en mi corazón una parte dedicada en especial para él donde le cuido y le quiero aunque a veces ello conlleve tomar decisiones o tener que actuar de maneras que a veces no comparta o a pesar de que me odie cuando no 
estoy disponible en el momento preciso que me necesita. Añadí entonces, que nuestra relación es ya tan sólida y estable que, aunque no me vea sabe que me puede buscar en su mente cuando lo necesite y que puede imaginar qué podría decirle o cómo podría ayudarle en esos momentos donde no estoy físicamente presente.

\section{Construyendo puentes en el espacio potencial del juego}

Además de las grandes aportaciones que Winnicott ha hecho al mundo de la psicología con sus ideas sobre el holding, handling y la madre suficientemente buena entre otras, creo que su reflexión y trabajo acerca del jugar es un tesoro que nos ofreció para repensar qué sucedía en el espacio de sesiones como un espacio potencial que conectaba de alguna manera la realidad exterior con la vida interior y las preocupaciones, angustias y emociones dentro de la cabeza de nuestros pacientes. Además, no sólo es el juego lo más importante sino el vínculo establecido entre paciente-terapeuta. Porque si éste es suficientemente bueno ofrecemos a los pacientes una segunda oportunidad para revivir experiencias traumatizantes con plena conciencia cuyo objetivo principal es poder integrarlas en una visión coherente de su self que le ayude a tener una sensación de continuidad y favorecer de esta manera un crecimiento pleno.

Sin embargo, jugar para mí no sólo implica crear un juego o una historia o un dibujo. Jugar significa crear. Citando a Winnicott "en el juego y sólo en él, puede el niño y el adulto crear y usar toda la personalidad, y el individuo descubre su personalidad sólo cuando se muestra creador" (1971, p.100). Invitando a nuestros pacientes a la reflexión estamos favoreciendo que encuentren el gusto de jugar con su mente, de salir del mundo de concreciones y poder pensar más allá. En definitiva, les estamos ayudando a ser curiosos de su propia mente y por ende con respecto al mundo que les rodea. Fomentar la curiosidad por uno mismo y por el mundo es un sinónimo de resiliencia y de salud mental. Durante mi trabajo me he encontrado con muchos pacientes, especialmente adolescentes, con una gran dificultad para pensar más allá. Muchos de ellos estaban asociados a consumos, o incluso a fracasos escolares tildados de TDAH donde lo que me encontraba en el trabajo con ellos era una capacidad muy pobre de mentalizar, de utilizar su mente de forma creativa y por lo tanto de poder hacer un uso adecuado de todo aquello que implique un mundo de abstracciones y asociaciones.

En casos así busco a través de la relación entre ambos ayudarles a pensar más allá. Una vez establecido un vínculo de confianza cuando me traen ideas vagas y pensamientos a medias con frases como "ya sabes", "pues eso...", "me dijo la misma movida de siempre...", etc. yo le animo a que me terminen esos pensamientos. A que les den forma, incluso a veces luego 
les ayudo parafraseando sus propias frases llenas de vaguedades. En muchas ocasiones incluso les digo directamente "vamos a jugar un poco con esa idea o pensamiento, ¿qué te sugiere? ¿a dónde se te va la cabeza?" Mi objetivo pasa por ponerlos a pensar, a indagar detalladamente como diría E. Levenson. Recuerdo a un adolescente que incluso en el interjuego dentro de las sesiones llegó a apodar su dificultad para mentalizar y acceder al plano simbólico su "Modo troglodita."

A veces no resulta sencillo ayudar a los pacientes a mentalizar. Muchas veces lleva tiempo e incluso tú necesitas durante un tiempo permitir la dependencia del paciente y acompañarle como una madre con su bebé de la mano mientras aprende a caminar por los senderos de la creatividad, el juego y la simbolización. Progresivamente podremos entonces ir soltando la mano y simplemente acompañarle en ese trayecto hasta que esté preparado.

\section{El humor como espacio de juego}

En mi práctica clínica he descubierto que el humor puede ser una forma muy placentera de jugar para ambos, particularmente con los adolescentes. Obviamente creo que es importante conocer cómo es la personalidad de la persona que tenemos en frente e incluso es importante que si nos encontramos ante patologías graves, con gran literalidad, el humor puede ser ajustado a su estructura y que de alguna manera pueda encontrar cierto beneficio en su uso en una relación de cuidado y de respeto.

Sandra Buechler (en Ávila, A., 2013) menciona la alegría como un "antídoto universal." Voy a citar aquí una de sus frases que he leído y releído muchas veces y a la que he recurrido en mi pensamiento en momentos de gran frustración y que me reconforta cada vez que la leo: "la alegría nos hace sentir que podemos volar por encima de los obstáculos frustrantes. Compensa la parálisis de la depresión y aminora la pena." (p.504.) He podido experimentar en mi propio trabajo cómo el uso del humor, de la broma y de la ironía ha podido ayudar a mis pacientes a liberarse de tensiones, ansiedades, culpas y vergüenzas. Es importante en este punto mencionar que el uso del humor tiene mucho que ver también con la personalidad de cada terapeuta y es evidente que uno tiene que sentirse cómodo utilizando este tipo de registro dentro de la consulta, pero también fuera en su propio entorno de relaciones.

Recuerdo con gran cariño sesiones de gran divertimento con tres pacientes. Dos de ellos con una patología dentro del espectro de la neurosis y otro chico con unos rasgos más de tipo borderline y con un pensamiento muy concreto y gran rigidez. 
En los dos primeros casos ambos compartían una capacidad intelectual elevada. Se sentían escasamente comprendidos por su grupo de iguales. Ambos casos tenían en común una sintomatología similar que tenía que ver con una ansiedad de separación y dificultades para la identificación con la figura paterna reactivadas en la llegada a la adolescencia, lo cual generaba un sentimiento de crisis en la construcción de su identidad, sintomatología ansiosa y dificultades para las relaciones con sus iguales. Fue costoso llegar a ellos, especialmente a uno de ellos cuya defensa narcisista dificultaba la relación en primera instancia. Sin embargo, pronto encontramos un punto en común, el uso de la ironía. Había sesiones con ellos que llegaban a ser ácidas en el humor. Ellos me comentaban dificultades y problemas y yo a veces les devolvía un señalamiento en tono de humor irónico. Sorprendentemente acogían esos señalamientos de una forma mucho más tranquila e incluso al escucharlo y poder reírse de ello y hacer bromas de vuelta de alguna manera se desligaba de aquella preocupación la angustia castrante, la vergüenza o la culpa, permitiendo una integración y aceptación de esos pensamientos y conllevando un mejor manejo social y familiar fuera además de una mejora de su sintomatología. En resumen, el uso del humor como forma de juego favoreció la salud de ambos adolescentes facilitó su crecimiento y por lo tanto las relaciones en los distintos grupos.

El otro caso es algo diferente. En este caso como ya he mencionado es un chico con una patología dentro de lo borderline. Con un funcionamiento muy concreto, gran rigidez y literalidad al inicio del trabajo. Aquí me encontré ante un caso donde el juego no era posible y mi labor como terapeuta era poder ayudar a este chico a transitar de una zona donde no era capaz de jugar a una donde fuera posible hacerlo (Winnicott, 1971.)

Este chico vino con diagnóstico de TDAH, fracaso escolar moderado y problemas de relación social serios debido a un funcionamiento en proceso primario y a una capacidad de represión pobre. Gran suspicacia, en parte infundada por una experiencia de acoso y una relación algo fusional madre e hijo que dificultaba su proceso de individuación y la adquisición adecuada de su autonomía. Había estado en varios psicólogos diferentes y venía de un trabajo terapéutico prolongado, aunque con escaso éxito. Dentro de la familia había ideas contrarias, el padre no quería medicarle y la madre se mostraba ambivalente a ello. Yo tampoco era partidaria de ello y en consenso con el psiquiatra del centro acordamos que comenzaría a trabajar con él sin medicación a expensas de ver cómo transcurría el curso escolar.

Al inicio el trabajo no fue fácil. Las sesiones con él resultaban lentas, algo aburridas e incluso carentes de contenido. Sin embargo, pude tener paciencia- a pesar de que a veces y especialmente en los inicios me frustraba cuando había sesiones vacías de contenido e 
intentaba llegar a jugar con el paciente y no podía. Pude ir construyendo una sólida relación terapéutica. La relación que ambos comenzamos a crear fue validando un self cada vez más seguro y autónomo hasta el punto de que comenzó a pedir a su madre que no estudiara más con él, que si suspendía era cosa suya y que deseaba intentarlo solo. La madre hizo grandes esfuerzos y permitió la ayuda y sostén que necesitó para cortar su cordón umbilical. Este adolescente recogió el testigo y se puso manos a la obra. Cuando esto sucedió las sesiones se volvieron más ricas. Su mirada seguía teniendo cierto tinte de vacuidad, pero el contacto, antes tan falto de afectividad, se iba enriqueciendo con cada sesión. Su sonrisa se tornó cada vez más sintónica y el humor comenzó a establecerse entre ambos. A veces un humor negro que tenía que ver con esas angustias más primarias características de sus rasgos más psicóticos, pero empezaron a aparecer cada vez más elementos neuróticos. Pudimos explorar incluso algunos elementos traumáticos además de su experiencia de acoso que también supusieron un desbloqueo y permitieron un crecimiento personal y favorecieron el desarrollo y maduración.

Su evolución comenzó a ser asombrosa. Su capacidad de mentalizar mejoró, su lenguaje se enriqueció y su capacidad de jugar y utilizar el humor y la ironía mejoró su interacción social. Han seguido teniendo lugar conflictos y problemas sociales fruto de su parte más primaria, pero a pesar de todo ha sido capaz de frenar, pensar y buscar en otros muchos momentos otras alternativas de solución, incluso llegando a mostrarse más maduro que su madre en la gestión de un conflicto ocurrido en clase. De hecho, aquí voy a hacer mención a Mitchell y a la importancia de cómo una experiencia relacional diferente puede favorecer un cambio en la matriz relacional del paciente. En el arriba mencionado conflicto, la madre se mostró invasiva con el colegio e incluso algo agresiva en las formas. Aunque respondía a una preocupación real por la integridad física de su hijo, las formas de decirlo y gestionarlo fueron desproporcionadas. Como ya he mencionado es una madre con tendencia a la invasión de los límites de otro. De esta manera solicitó información confidencial acerca del otro chico implicado en el conflicto. Evidentemente el colegio se negó a ofrecerla y ella no consiguió comprenderlo hasta que su hijo le dijo "mamá, entiende que igual que yo lo que hablo con Carmen es privado y no me gustaría que dijera a nadie de qué hablamos, entiende que no puedes pretender que ellos te den una información confidencial de este chico, así que deja que lo resuelvan ellos." Así, quiero ejemplificar cómo el trabajo desde la individuación y el respeto hacia la subjetividad e intimidad de este paciente pudo favorecer el crecimiento de una nueva dinámica relacional que rompe con la historia de fusión y difusión de límites intersubjetivos a poner en valor la importancia de respetar la intimidad y los límites de otro.

No sólo mejoró en lo social, sino que cogió las riendas de los estudios. Pasó de ser un chico dependiente en los estudios a comenzar a hacerse sus esquemas, resúmenes y a tener éxito 
con sus exámenes. Su rendimiento mejoró con creces, pasó de curso y pudo gestionar los primeros fracasos y suspensos, así como los encontronazos con los profesores de forma suficientemente madura y respetuosa. Hoy es el momento donde está teniendo gran éxito académico sin necesidad de ningún tipo de medicación.

Recientemente, su madre, -quien en innumerables ocasiones me ha hecho saber de su gratitud y de la importancia que tiene para su hijo (y para toda la familia) el vínculo que hemos creado entre ambos- que éste le dijo: "mamá, me gusta ir a hablar con Carmen porque le cuento las cosas y nunca se enfada. Me escucha y me ayuda a ver otras maneras de resolver las cosas y de pensar acerca de ellas." Me conmovió escuchar esto porque define exactamente cómo entiendo yo la psicoterapia y en especial aquella que se hace con los niños y adolescentes donde queremos que en el futuro sean personas que mentalicen y formen parte de una sociedad que cada vez está más vacía de valores, pensamientos y emociones.

\section{El espacio terapéutico como zona de comunicación entre lo interno y externo}

Hablando de humor e introduciendo así la última parte de mi trabajo quiero traer a la mente de los lectores una escena de Mafalda representada por su hermano pequeño Guille. En dicha escena aparecen todas las paredes de la habitación pintadas y en la esquina la madre de Guille le mira resignada mientras su hijo le dice "¿No ez increíble todo lo que puede tened adentro un lápiz?" Esta misma pregunta me la hago yo muchas veces cuando finalizo una sesión de juego con mis pacientes. A veces incluso yo sigo sorprendiéndome -y espero no perder esta capacidad de sorprenderme nunca- de todo lo que puede surgir dentro de una misma escena de juego.

A continuación, traigo una sesión de juego que tuvo lugar con una chica de 10 años con mutismo y cómo pudimos ambas superponer nuestras dos zonas de juego y el papel que posee el juego como espacio potencial para el cambio. Winnicott (1971) definía espacio de juego como "un área de experiencia compartida donde dos subjetividades se encuentran, se afirman, y se reconocen." El trabajo con esta chica es muy especial porque llevamos trabajando durante un año y medio aproximadamente sin mediar ni una sola palabra y a pesar de todo hemos encontrado entre ambas una forma de comunicación a través de dibujos, gestos, juego y recientemente la escritura como forma de comunicación. A pesar de no hablar en consulta, fuera se están dando muchos movimientos de apertura y comunicación que permiten confirmar que el trabajo dentro de la sesión es fructífero. A continuación, expongo la transcripción que hice tras la sesión de juego. 
Comienza construyendo una cárcel. Una cárcel con muros altos y ventanas pequeñas y cerradas. La cárcel está aislada con agua alrededor. Le señalo esto y lo relaciono con la sensación de estar incomunicada, sin contacto con el exterior, algo que me recuerda un poco cómo a ella misma le pasa con su incapacidad para hablar. La persona dentro debe sentirse sola y apartada, le digo. Entonces, comienza a construir al otro lado del agua casas a lo lejos. Casas pequeñas pero que simbolizan la presencia de alguien al otro lado. Le señalo que parece que hay cierto contacto con el exterior y seguido ella abre las mini ventanas de la cárcel. A pesar de todo le señalo de nuevo que parece que, aunque hay presencia de un pueblo a lo lejos -y por lo tanto no se siente tan aislada -la persona encarcelada sigue estando lejos y separada del pueblo por un gran mar que le impide llegar allá. Ante esto comienza a construir puentes. En ese momento le señalo que parece que ahora comienza a haber una posibilidad de comunicación mayor, que la persona ya tiene la posibilidad de cruzar al pueblo o bien que el pueblo sea quien vaya a visitarle.

De esta manera, permite la comunicación entre dos escenarios que antes estaban totalmente separados. Una comunicación entre ella y el ambiente, entre lo interno y lo externo. Al finalizar la sesión yo hago un resumen de lo que se ha puesto en escena en el juego y le señalo que me recuerda un poco a como ella le ha ido pasando de sentirse encerrada y prisionera de sus palabras y sus silencios a que poco a poco ha podido ir construyendo puentes que permiten una mejor comunicación con el exterior.

\section{Conclusión}

Son muchas las experiencias que me quedan por transitar y ante eso espero, que como dije más arriba, no perder nunca la capacidad de sorprenderme, porque ello significará que sigo teniendo una mente creativa, una mente curiosa que está deseosa de crecer y aprender.

Winnicott me aporta seguridad a la hora de trabajar. Sé que sin duda erraré y meteré la pata, pero también confío en ser una terapeuta lo suficientemente buena que después pueda repensarlo, repararlo y trabajarlo con mi paciente con el objetivo de ofrecerle experiencias relacionales nuevas que le puedan movilizar al crecimiento personal y en todos los ámbitos de su vida.

Este autor ha hecho aportaciones enormes al modo de pensar qué papel podemos tener en la vida de nuestros pacientes y cómo podemos marcar una huella que puede generar múltiples beneficios; sin embargo, no somos perfectos y por lo tanto semejante responsabilidad también conlleva un riesgo. Un riesgo que es menor si podemos buscar puntos de apoyo que nos ayuden a ver nuestros propios puntos ciegos, nuestras 
resistencias o a que nos abran caminos que no se nos habían ocurrido. De ahí la importancia de una supervisión y trabajo personal que resulta a la vez doblemente enriquecedor para uno mismo y para nuestros pacientes.

Bajo mi forma de leer a Winnicott este autor nos enseña a ser espontáneos, a no tener miedo al fallo si se sabe reparar y a salir del encorsetamiento de la teoría y permitirnos ser espontáneos con nuestros pacientes. A veces queremos ser tan pulcros a nivel técnico que nos olvidamos de disfrutar y de fluir con las personas que tenemos en frente y perdemos oportunidades de salir al encuentro de temas maravillosos que pueden abrir muchas puertas en el trabajo analítico.

\section{REFERENCIAS}

Abello, A. y Liberman, A. (2011). Una introducción a la obra de D. W. Winnicott. Madrid: Ágora Relacional, Col. Pensamiento Relacional $n^{\circ} 3$.

Buechler, S. (2013). El psicoanálisis interpersonal, tal como yo lo veo. En Ávila Espada, A. (ed.) (2013), La tradición interpersonal. Perspectiva social y cultural en psicoanálisis, (pp.497-537.) Madrid: Ágora Relacional no 8.

Freud, S. (1920). Más allá del principio de placer. En Obras Completas. AE, XVIII. Buenos Aires: Amorrotu ed., 2013.

Mitchell, S. A. (1993). Conceptos relacionales en psicoanálisis: Una integración. México: Siglo XXI.

Palacio, F. y Dufour, R. (2003). Diagnóstico estructural en el niño. España: Herder.

Winnicott, D. (1953). Objetos transicionales y fenómenos transicionales. International Journal of psycho-analysis, vol 34., Segunda parte 1953.

Winnicott, D. (1958). The Capacity to be alone. International Journal of Psycho-Analysis, 39:416420.

Winnicott, D. (1971) Realidad y Juego. Barcelona: Gedisa, 2013.

Original recibido con fecha: 19/7/2019 Revisado: 30/9/2019 Aceptado: 30/9/2019 